\title{
Comparison of Dexmedetomidine with Fentanyl in Attenuation of Pressor Response during Laryngoscopy and Intubation
}

\author{
${ }^{1,}$ Dr Sagar Gandhi , ${ }^{2,}$ Dr VigyaGoyal , ${ }^{3,}$ Dr Krishnaprabha Radhakrishnan , \\ ${ }^{4}$ Dr Mahesh Balakrishnan \\ ${ }^{I}$,Practisinganaesthetist \\ 2, $3^{\text {nd }}$ year resident,$B J M C$ Ahmedabad \\ 3, $3^{\text {rd }}$ year resident ,BJMC Ahmedabad \\ 4, $2^{\text {rd }}$ year resident, BJMC Ahmedabad
}

\section{ABSTRACT \\ INTRODUCTION}

The pressure response, which is part of a huge spectrum of stress response, results from the increase in sympathetic and sympathoadrenalactivity.Acomparision between dexmeditomedine and fentanyl in suppressing the pressorresponse is studied.

\section{OBJECTIVE}

This study was done to compare the effectiveness of Dexmedetomidine with Fentenyl in attenuating the pressor responses associated with laryngoscopy and endotracheal intubation in groups belonging to normotensive ASA grade 1, 2 risk surgical patients.

MATERIAL

The study was carried out on 100 patients belonging to ASA grade I and II, aged 15 to 65 years, including either gender, scheduled for elective surgical procedures under general anesthesia.

\section{RESULT}

DEXMEDETOMIDINE when used as I.V. premedicant in dose of $0.6 \mu \mathrm{g} / \mathrm{kg}$ provides beneficial effect in attenuation of pressor response to laryngoscopy and endotracheal intubation as compare to FENTANYL in dose of $2 \mu \mathrm{g} / \mathrm{kg}$.

\section{INTRODUCTION}

Intubation has been practiced following its description by Rowbatham and Magill in 1921. The circulatory responses to laryngeal and tracheal stimulation following laryngoscopy and intubation were documented by Reid and Brace in 1940 and king et al in 1951. The pressure response, which is part of a huge spectrum of stress response, results from the increase in sympathetic and sympathoadrenal activity, as evidence by increased plasma catecholamines concentration in patients undergoing surgery under general anaesthesia. Increase in mean arterial pressure of an average of $25 \mathrm{~mm} \mathrm{Hg}$ was observed in normotensive patients following laryngoscopy and intubation under anesthesia with thiopentone, nitric oxide, oxygen and suxamethonium.

The rise in the heart rate and blood pressure is usually transient, variable and unpredictable. Usually these changes are well tolerated by healthy individuals. However these changes may be fatal in patient with hypertension, coronary artery disease or intracranial hypertension. Left ventricular failure, myocardial ischemia, cerebral hemorrhage may occur in high risk patients. Convulsions may be precipitated in pre-eclamptic patients To blunt this pressor response, various methods have been tried including,

- Deeper plane of anaesthesia with intravenous or inhalation agent

- Use of Propofol

- Curtailing the duration of laryngoscopy to less than 15 seconds

- Sympathetic blockage

- Lidocaine spray or gargles 3 minutes prior to intubation

- Use of intravenous Lidocaine to blunt the pressor response

- Use of ACE inhibitors e.g. Captopril, Enalapril 45 minutes prior to intubation

- Use of Magnesium sulphate

- Various antihypertensive and vasodilators e.g. IV Hydralazine, $\mathrm{Ca}^{+2}$ channel blocker like Nifedipine, beta blockers like Esmolol

- Use of Nicardipine

- Use of Opiods prior to induction e.g. Fentanyl, SuFentanyl or AlFentanyl 
- Use of Nitroglycerine ointment, intravenous, sublingual spray, intranasal spray

- Use of Gabapentin

- Alpha -2 agonists like Clonidine

\section{Patient selection :}

\section{MATERIAL AND METHOD}

- After approval from ethical committee, civil hospital, Ahmedabad, the study was carried out on 100 patients belonging to ASA grade I and II, aged 15 to 65 years, including either gender, scheduled for elective surgical procedures under general anesthesia.

\section{EXCLUSION CRITERIA:}

The patients with baseline heart rate $<60 \mathrm{bpm}$, baseline blood pressure $<100 / 50 \mathrm{~mm}$ of $\mathrm{Hg}$, reactive airway disease, history of cardiac disease and hypertensive patient, on treatment with adrenergic augmenting or depleting drugs, PR interval $>0.24$ seconds on ECG, $2^{\text {nd }}$ and/or $3^{\text {rd }}$ degree heart block, requiring 2 or more attempts for laryngoscopy and intubation were excluded from the study. Patients were randomly divided into two groups of 50 each. Group D received $0.6 \mathrm{mcq} / \mathrm{kg}$ Dexmedetomidine and Group F received $2 \mathrm{mcq} / \mathrm{kg}$ Fentanyl diluted in $10 \mathrm{ml}$ normal saline 10 minutes before laryngoscopy and intubation.

\section{Preoperative evaluation :}

- Patients were subjected to routine investigations like blood sugar, Hb level, renal and liver function test.

- Airway of patients that were likely to be anticipated for difficult intubation was evaluated.

\section{Preoperative preparation :}

- The procedure was explained to the patient and written informed consent was taken.

- All patients were preloaded with crystalloid fluid, $8-10 \mathrm{ml} / \mathrm{kg}$.

- All patients were pre-medicated with inj. Glycopyrrolate $0.04 \mathrm{mg} / \mathrm{kg}$ iv and inj.Ondansetron $0.15 \mathrm{mg} / \mathrm{kg}$ i.v.

- Heart rate, systolic and diastolic blood pressure was recorded before pre-medication and 10 minutes after pre-medication in patients.

\section{Selection of groups:}

(1) Group D - Dexmeditomidine $(0.6 \mathrm{mcg} / \mathrm{kg}$ diluted in $5 \mathrm{ml}$ saline IV over $1 \mathrm{~min})$

(2) Group F - Fentanyl ( $2 \mathrm{mcg} / \mathrm{kg}$ diluted in $5 \mathrm{ml}$ saline IV over $1 \mathrm{~min}$ )

\section{METHOD OF STUDY :}

- With patient in supine position, Injection DEXMEDETOMIDINE $0.6 \mathrm{mcq} / \mathrm{kg}$ diluted in $10 \mathrm{ml}$ saline and Injection FENTANYL $2 \mathrm{mcq} / \mathrm{kg}$ diluted in $10 \mathrm{ml}$ saline in groups D and F respectively, were administered intranvenously 10 minutes before laryngoscopy and intubation.

- Heart rate, systolic and diastolic blood pressure, $\mathrm{SPO}_{2}$ was recorded at 1 minute interval of drug administration.

- Patients were induced with inj. Pentothal (4-7 mg/kg) i.v. and inj. Suxamethonium $(2 \mathrm{mg} / \mathrm{kg})$ i.v. followed by Laryngoscopy and intubation.

- Variables to be monitored were heart rate, systolic blood pressure, diastolic blood pressure, $\mathrm{SPO}_{2}$ and ECG.

- All parameters were recorded at following stages:

Before pre-medication (BPM)

After pre-medication (APM)

30 seconds after endotracheal intubation (AEI)

And then every one minute up to 10 minute (AEI)

- All intubation were accomplished within 15 seconds by an expert anaesthesiologist.

- Only one attempt of intubation was accepted in the study.

- Patient who had coughed or bucked during procedure were excluded from study.

- After intubation, patients were maintained with Isoflurane $(0.4 \% \mathrm{v} / \mathrm{v})$ or Sevoflurane $(0.8 \% \mathrm{v} / \mathrm{v}), \mathrm{O}_{2}(50 \%)$ , $\mathrm{N}_{2} \mathrm{O}(50 \%)$ and non-depolarizing muscle relaxant.

- At the end of surgery, patients were reversed with inj. Glycopyrrolate and inj. Neostigmine.

Patients were watched for any complication like tachycardia, hypotension, arrhythmias, bronchospasm during intraoperative and post operative period

This study was conducted to evaluate the efficacy of intravenous Dexmedetomidine and Fentanyl in attenuation of stress response to laryngoscopy and intubation. A hundred adult patients of either gender, belonging to ASA grade I or II were selected for the study. Statistical data wasanalyzed by using Z test wherever required. 
(1) Patient demographics :

a) Age:

The mean age of the patients in group D and F were $37.76 \pm 10.41$ years and $38.96 \pm 9.94$ respectively.

b) Weight :

The mean weight of patients in groups $\mathrm{D}$ and $\mathrm{F}$ were $63.7 \pm 6.57$ and $64.58 \pm 5.16$ respectively

Table 1. Demographic data

\begin{tabular}{|c|c|c|c|c|}
\hline & \multirow{2}{*}{$\begin{array}{c}\text { Age } \\
\text { (in years) }\end{array}$} & \multicolumn{2}{|c|}{ Number of Patients } & \multirow{2}{*}{$\begin{array}{l}\text { Weight } \\
\text { (in kgs) }\end{array}$} \\
\hline & & Males & Females & \\
\hline $\begin{array}{c}\text { Group D } \\
\text { (DEXMEDETOMIDIN } \\
\text { E }\end{array}$ & $37.76 \pm 10.41^{*}$ & 20 & 30 & $63.7 \pm 6.57^{*}$ \\
\hline $\begin{array}{c}\text { Group F } \\
\text { (FENTANYL) }\end{array}$ & $38.96 \pm 9.94 *$ & 21 & 29 & $64.58 \pm 5.16^{*}$ \\
\hline
\end{tabular}

Age and weight of the all patients in both groups are comparable to each other and there is no statistical difference between them $(*$ - p value $>0.05)$.

Figure 1. Mean age of the patients in all groups $(n=100)$

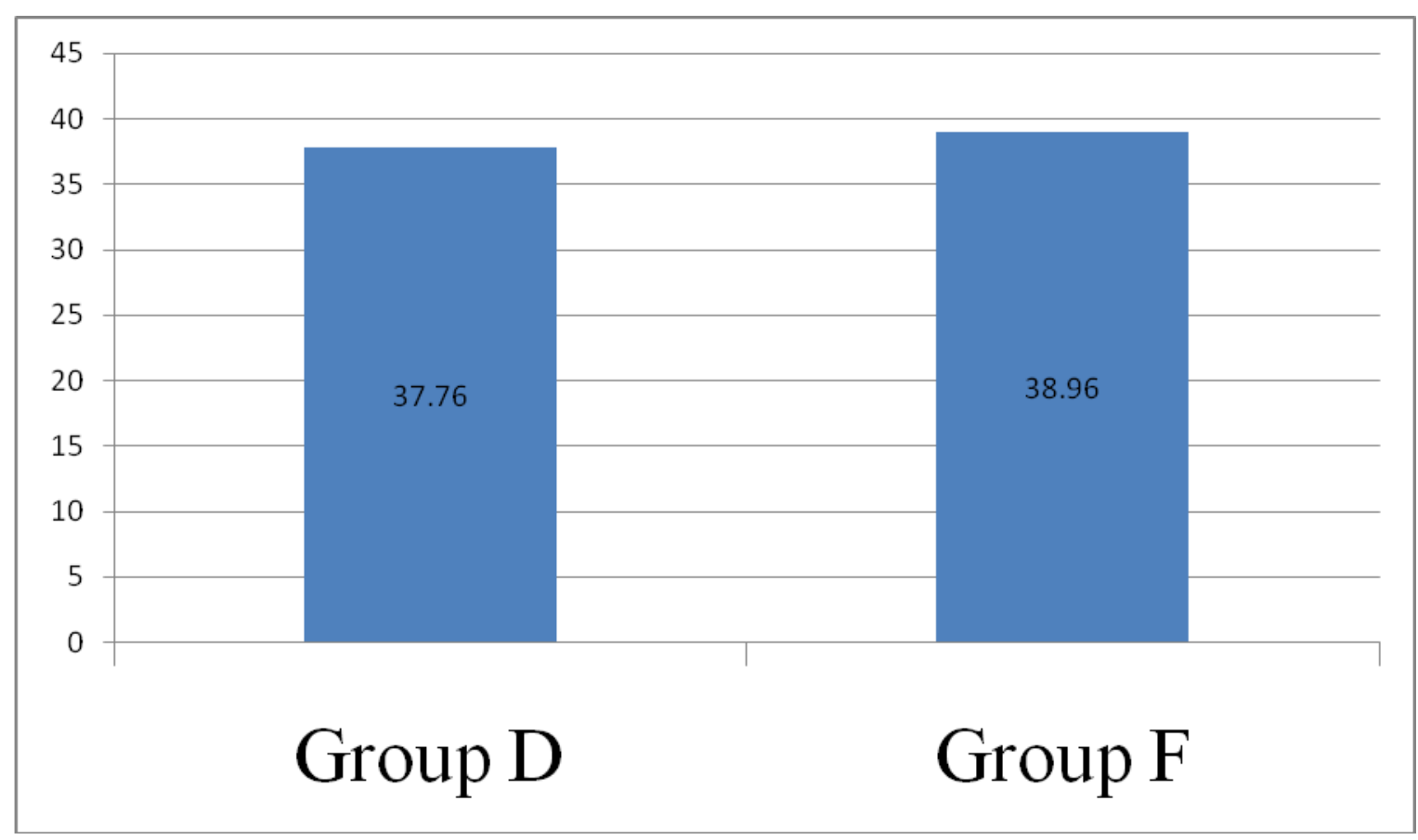

Figure 2. Mean weight of the patients in all groups $(n=100)$ 


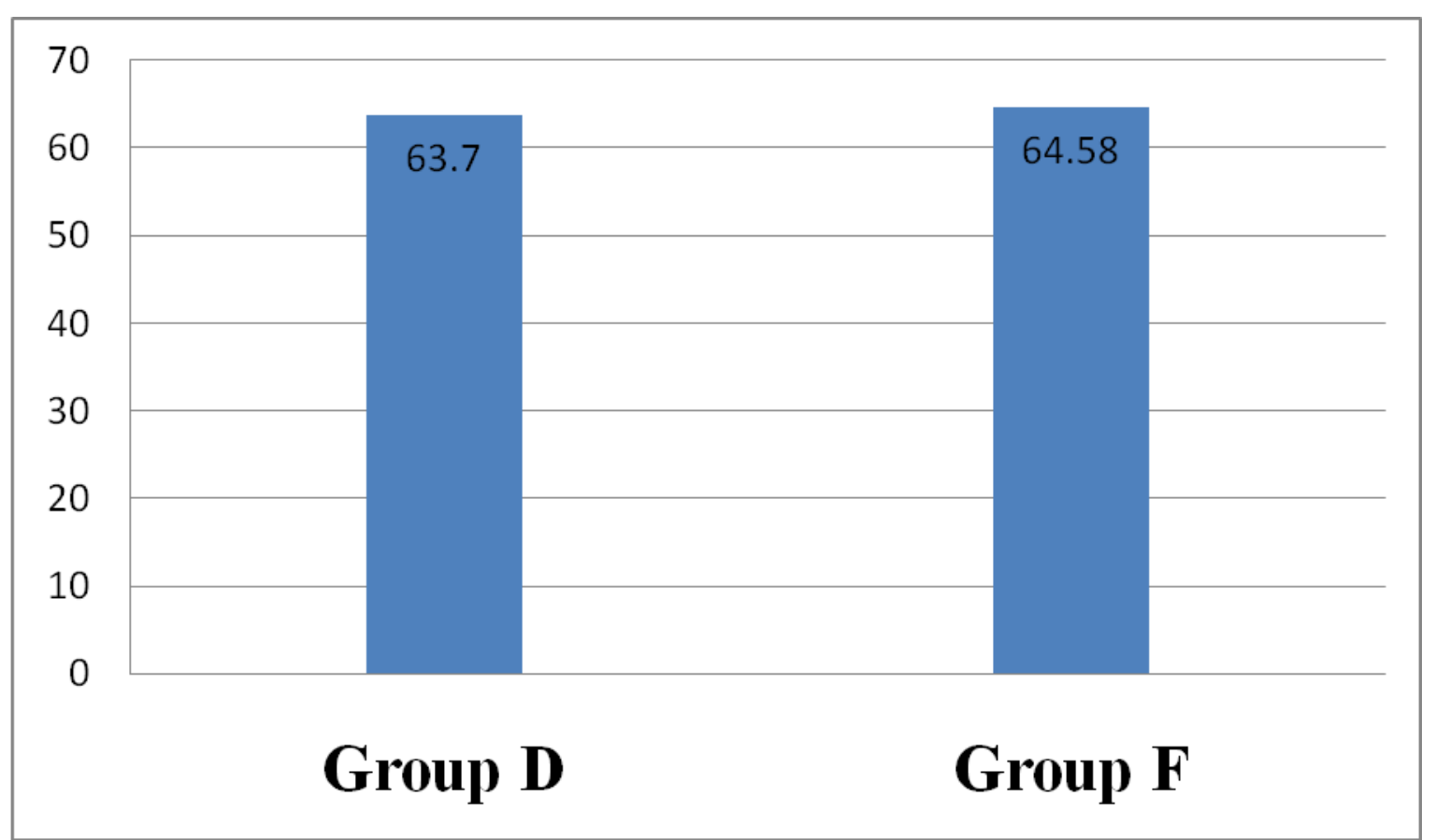

(2 ) HEART RATE:

The heart rate was measured at baseline, after IV premedication for every one minute interval till 10 minutes, during laryngoscopy and intubation and for every one minute till 10 minutes after intubation (Table 2 ). It was observed that the heart rate increased in both groups immediately after endotracheal intubation. The heart rate started to return to normal values at the end of 10 minutes post intubation.

Table 2. Changes in heart rate

\begin{tabular}{|l|l|l|l|l|l|l|l|l|l|}
\hline \multicolumn{2}{|c}{$\begin{array}{c}\text { Heart rate } \\
\text { (beats per } \\
\text { Minute) }\end{array}$} & $\begin{array}{l}\text { At } \\
\text { baseline }\end{array}$ & $\begin{array}{l}10 \mathrm{~min} \\
\text { after } \\
\text { premed }\end{array}$ & $\begin{array}{l}1 \mathrm{~min} \\
\text { after ETI }\end{array}$ & $\begin{array}{l}2 \mathrm{~min} \\
\text { after ETI }\end{array}$ & $\begin{array}{l}3 \text { min } \\
\text { after ETI }\end{array}$ & $\begin{array}{l}5 \text { min } \\
\text { after ETI }\end{array}$ & $\begin{array}{l}7 \mathrm{~min} \\
\text { after ETI }\end{array}$ & $\begin{array}{l}10 \mathrm{~min} \\
\text { after } \\
\text { ETI }\end{array}$ \\
\hline \multirow{2}{*}{ Group D } & $\begin{array}{l}\text { Mea } \\
\text { n }\end{array}$ & $82.78 \#$ & $68.88^{*}$ & $76.2^{*}$ & $78.6^{*}$ & $78.22^{*}$ & $73.38^{*}$ & $70.76^{*}$ & $68.58^{*}$ \\
\cline { 2 - 10 } & \pm SD & $9.18 \#$ & $9.68^{*}$ & $11.88^{*}$ & $11.91^{*}$ & $13.42^{*}$ & $10.74^{*}$ & $10.34^{*}$ & $9.83^{*}$ \\
\hline \multirow{2}{*}{ Group F } & $\begin{array}{l}\text { Mea } \\
\text { n }\end{array}$ & $82.04 \#$ & $80.3^{*}$ & $94.28^{*}$ & $99.48^{*}$ & $98.54^{*}$ & $94.22^{*}$ & $92.28^{*}$ & $90.34^{*}$ \\
\cline { 2 - 10 } & \pm SD & $10.11 \#$ & $10.35^{*}$ & $9.50^{*}$ & $11.88^{*}$ & $11.25^{*}$ & $10.54^{*}$ & $11.18^{*}$ & $12.15^{*}$ \\
\hline
\end{tabular}

\# - Base line heart rate of all patients of both groups are comparable to each other and there is no statistical difference between them ( $\mathrm{p}$ value $>0.05$ ).

*-The increase was highly significant in group $\mathrm{F}$ as compared to group D during laryngoscopy and after intubation ( $p$ value $<0.001$ ). 
Figure 3. Heart rate in all groups at various time intervals

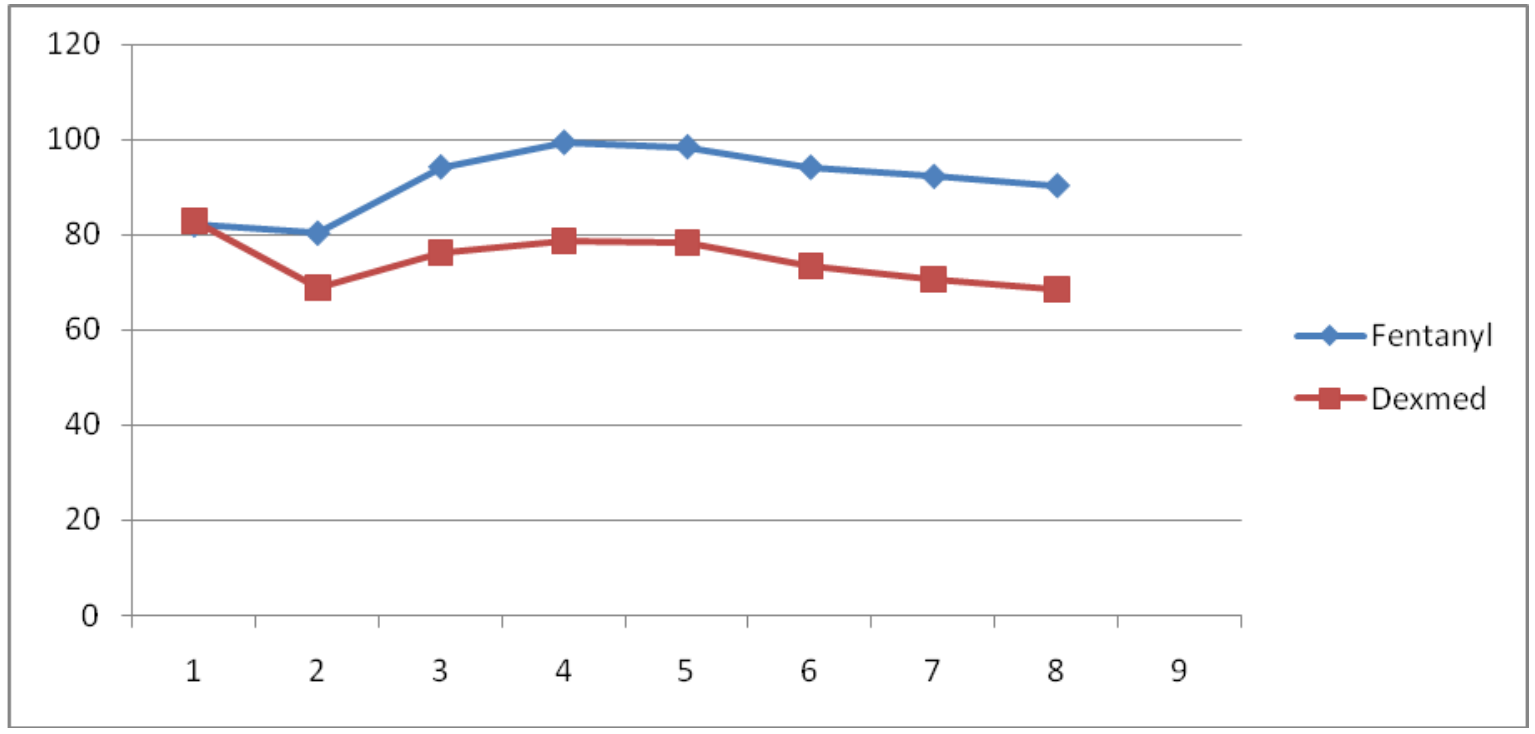

(3) Systolic blood pressure:

The systolic blood pressure was measured at baseline, after IV premedication for every one minute interval till 10 minutes, during laryngoscopy and intubation and for every one minute till 10 minutes after intubation (Table 3). It was observed that the systolic blood pressure increased in both groups immediately after endotracheal intubation. The systolic blood pressure started to return to normal values at the end of 10 minutes post intubation.

Table 3. Changes in systolic blood pressure

\begin{tabular}{|l|l|l|l|l|l|l|l|l|l|}
\hline \multicolumn{2}{|l|}{$\begin{array}{l}\text { Systolic blood } \\
\text { pressure } \\
(\mathbf{m m H g})\end{array}$} & $\begin{array}{l}\text { At } \\
\text { baseline }\end{array}$ & $\begin{array}{l}10 \mathrm{~min} \\
\text { after } \\
\text { premed }\end{array}$ & $\begin{array}{l}1 \mathrm{~min} \\
\text { after } \\
\text { ETI }\end{array}$ & $\begin{array}{l}2 \mathrm{~min} \\
\text { after } \\
\text { ETI }\end{array}$ & $\begin{array}{l}3 \mathrm{~min} \\
\text { after } \\
\text { ETI }\end{array}$ & $\begin{array}{l}5 \text { min } \\
\text { after ETI }\end{array}$ & $\begin{array}{l}7 \text { min } \\
\text { after ETI }\end{array}$ & $\begin{array}{l}10 \mathrm{~min} \\
\text { after ETI }\end{array}$ \\
\hline $\begin{array}{l}\text { Group } \\
\text { D }\end{array}$ & Mean & $130.88 \#$ & $112.96^{*}$ & $122.96^{*}$ & $125.24^{*}$ & $122.32^{*}$ & $116.04^{*}$ & $111.6^{*}$ & $107.1^{*}$ \\
\cline { 2 - 10 } & \pm SD & $8.52 \#$ & $10.86^{*}$ & $14.47^{*}$ & $15.19^{*}$ & $15.40^{*}$ & $14.21^{*}$ & $12.94^{*}$ & $10.78^{*}$ \\
\hline $\begin{array}{c}\text { Group } \\
\text { F }\end{array}$ & Mean & $129.38 \#$ & $121.58^{*}$ & $131.44^{*}$ & $146.56^{*}$ & $143.14^{*}$ & $135.46^{*}$ & $126.56^{*}$ & $117.72^{*}$ \\
\cline { 2 - 9 } & \pm SD & $9.97 \#$ & $9.98^{*}$ & $7.28^{*}$ & $7.99^{*}$ & $7.62^{*}$ & $7.02^{*}$ & $7.56^{*}$ & $4.73^{*}$ \\
\hline
\end{tabular}

\# - Base line systolic blood pressore of all patients of both groups are comparable to each other and there is no statistical difference between them ( $p$ value $>0.05$ ).

*- The increase was highly significant in group $\mathrm{F}$ as compared to group D during laryngoscopy and after intubation $(\mathrm{p}<0.001)$. 
Figure 4. Systolic blood pressure in all groups at various time intervals

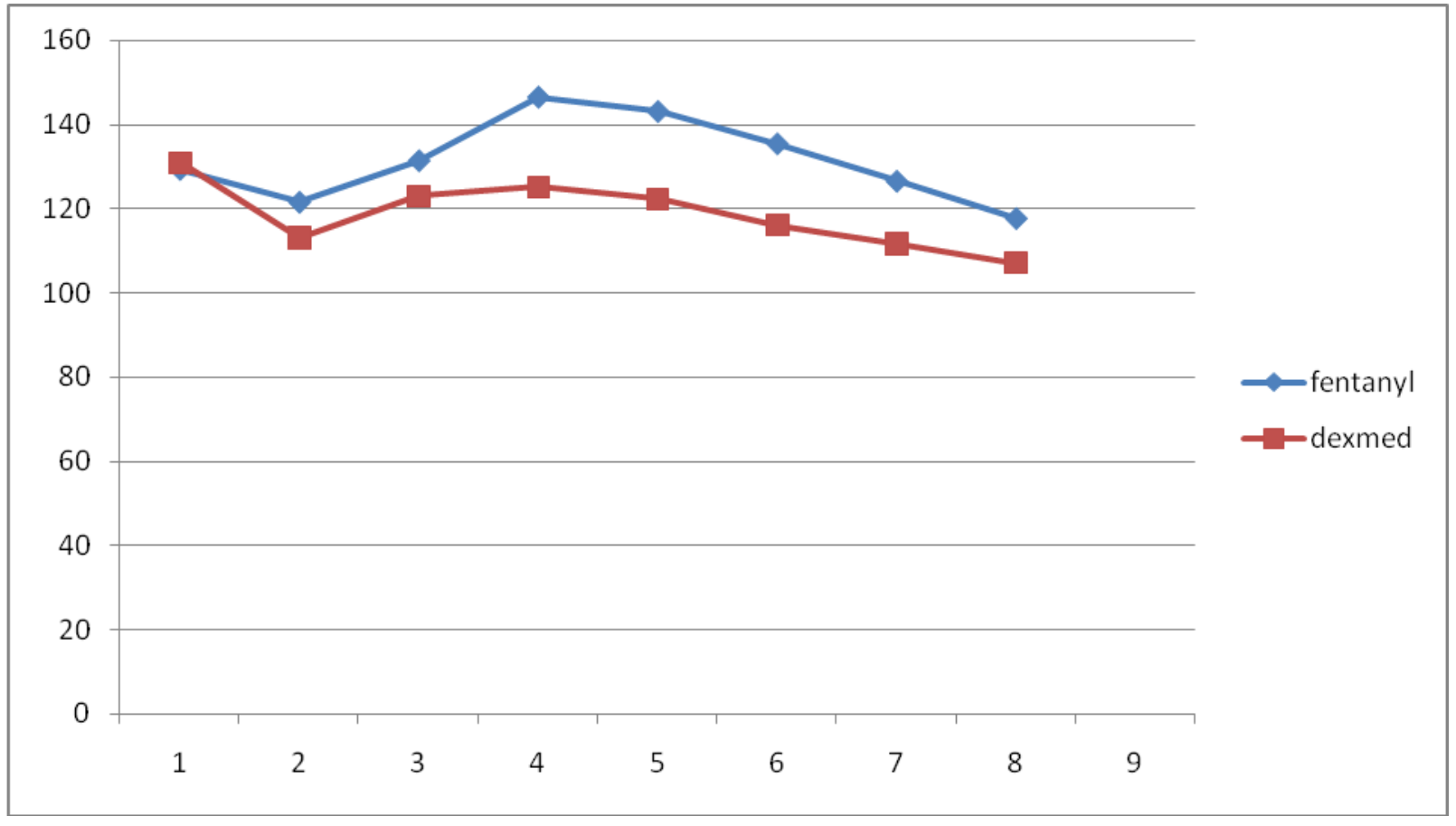

(4) Diastolic blood pressure:

The diastolic blood pressure was measured at baseline, after IV premedication for every one minute interval till 10 minutes, during laryngoscopy and intubation and for every one minute till 10 minutes after intubation (Table 4). It was observed that the diastolic blood pressure was increased significantly from the baseline during laryngoscopy and after intubation in both groups and returned to normal at the end of 10 minutes post intubation in all the groups.

Table 4. Changes in Diastolic blood pressure

\begin{tabular}{|c|l|l|l|l|l|l|l|l|l|}
\hline \multicolumn{2}{|c|}{$\begin{array}{c}\text { Systolic blood } \\
\text { pressure } \\
\text { (mmHg) }\end{array}$} & $\begin{array}{l}\text { At } \\
\text { baseline }\end{array}$ & $\begin{array}{l}10 \mathrm{~min} \\
\text { after } \\
\text { premed }\end{array}$ & $\begin{array}{l}1 \mathrm{~min} \\
\text { after } \\
\text { ETI }\end{array}$ & $\begin{array}{l}2 \mathrm{~min} \\
\text { after } \\
\text { ETI }\end{array}$ & $\begin{array}{l}3 \text { min } \\
\text { after ETI }\end{array}$ & $\begin{array}{l}5 \mathrm{~min} \\
\text { after ETI }\end{array}$ & $\begin{array}{l}7 \text { min } \\
\text { after } \\
\text { ETI }\end{array}$ & $\begin{array}{l}10 \mathrm{~min} \\
\text { after ETI }\end{array}$ \\
\hline Group D & Mean & $78.32 \#$ & $69.02^{*}$ & $75.1^{*}$ & $77.12^{*}$ & $75.7^{*}$ & $71.72^{*}$ & $68.42^{*}$ & $65.92^{*}$ \\
\cline { 2 - 10 } & \pm SD & $5.65 \#$ & $8.09^{*}$ & $10.76^{*}$ & $10.74^{*}$ & $10.13^{*}$ & $9.50^{*}$ & $9.03^{*}$ & $7.65^{*}$ \\
\hline \multirow{2}{*}{ Group F } & Mean & $77.08 \#$ & $73.48^{*}$ & $78.38^{*}$ & $82.68^{*}$ & $81.72^{*}$ & $80.26^{*}$ & $78.88^{*}$ & $77.14^{*}$ \\
\cline { 2 - 9 } & \pm SD & $2.57 \#$ & $3.13^{*}$ & $2.81^{*}$ & $2.90^{*}$ & $2.49^{*}$ & $2.36^{*}$ & $1.61^{*}$ & $1.95^{*}$ \\
\hline
\end{tabular}

\# - Base line diastolic blood pressore of all patients of both groups are comparable to each other and there is no statistical difference between them ( $\mathrm{p}$ value $>0.05$ ).

* - The increase was highly significant in group F as compared to group D during laryngoscopy and after intubation $(\mathrm{p}<0.001)$. 
Figure 5.Diastolic Blood Pressure in all groups at various time intervals

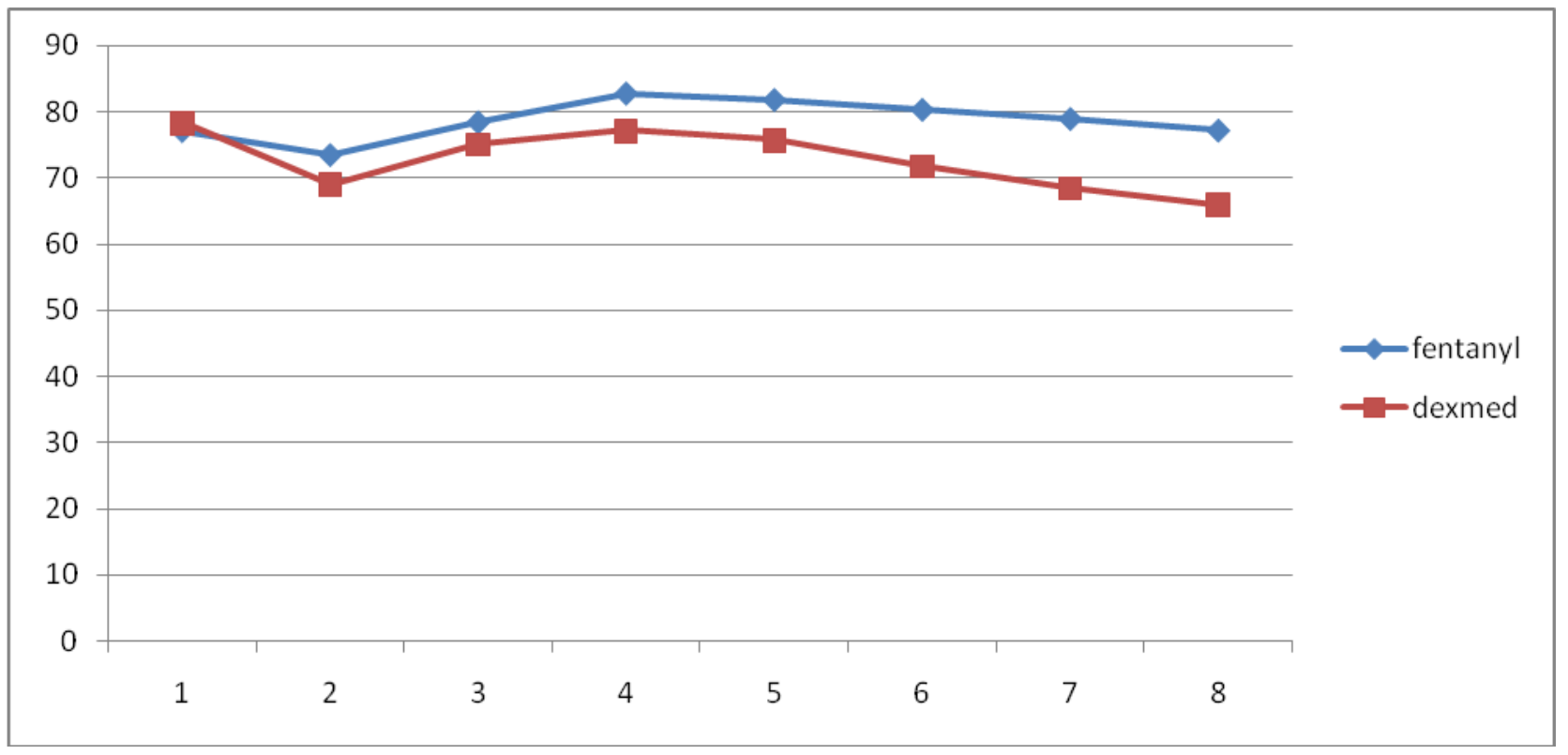

(5) Mean Arterial Blood Pressure:

The mean arterial blood pressure was measured at baseline, after IV premedication for every one minute interval till 10 minutes, during laryngoscopy and intubation and for every one minute till 10 minutes after intubation (Table 5). It was observed that the mean arterial blood pressure was increased significantly from the baseline during laryngoscopy and after intubation in both groups and returned to normal at the end of 10 minutes post intubation in all the groups.

Table 5. Changes in Mean Arterial Pressure

\begin{tabular}{|l|l|l|l|l|l|l|l|l|l|}
\hline \multicolumn{2}{|c}{$\begin{array}{c}\text { Mean arterial } \\
\text { pressure } \\
\text { (mmHg) }\end{array}$} & $\begin{array}{l}\text { At } \\
\text { baseline }\end{array}$ & $\begin{array}{l}10 \mathrm{~min} \\
\text { after } \\
\text { premed }\end{array}$ & $\begin{array}{l}1 \mathrm{~min} \\
\text { after } \\
\text { ETI }\end{array}$ & $\begin{array}{l}2 \mathrm{~min} \\
\text { after } \\
\text { ETI }\end{array}$ & $\begin{array}{l}3 \mathrm{~min} \\
\text { after ETI }\end{array}$ & $\begin{array}{l}5 \mathrm{~min} \\
\text { after ETI }\end{array}$ & $\begin{array}{l}7 \mathrm{~min} \\
\text { after ETI }\end{array}$ & $\begin{array}{l}10 \mathrm{~min} \\
\text { after ETI }\end{array}$ \\
\hline \multirow{2}{*}{$\begin{array}{l}\text { Group } \\
\text { D }\end{array}$} & Mean & $95.66 \#$ & $83.52^{*}$ & $90.89^{*}$ & $93^{*}$ & $91.08^{*}$ & $86.35^{*}$ & $82.67^{*}$ & $79.51^{*}$ \\
\cline { 2 - 10 } & \pm SD & $5.95 \#$ & $8.64^{*}$ & $11.44^{*}$ & $11.76^{*}$ & $12^{*}$ & $10.77^{*}$ & $9.95^{*}$ & $8^{*}$ \\
\hline Group F & Mean & $94.34 \#$ & $89.35^{*}$ & $95.89^{*}$ & $103.76^{*}$ & $101.99^{*}$ & $98.48^{*}$ & $94.61^{*}$ & $90.53^{*}$ \\
\cline { 2 - 10 } & \pm SD & $3.69 \#$ & $4.13^{*}$ & $3.20^{*}$ & $3.30^{*}$ & $3.36^{*}$ & $2.98^{*}$ & $2.85^{*}$ & $2.22^{*}$ \\
\hline
\end{tabular}

\# - Base line Mean Arterial Blood Pressure of all patients of both groups are comparable to each other and there is no statistical difference between them ( $\mathrm{p}$ value $>0.05$ ).

* - The increase was highly significant in group F as compared to group D during laryngoscopy and after intubation $(\mathrm{p}<0.001)$.

(6) Effect OfDexmedetomodine On Hemodynamic Parameter:

After pre medication with Dexmedetomidine, initially there is a increase in blood pressure after that there is decrease in blood pressure. Heart rate decrease after application of Dexmedetomidine. 
Figure 6 : Effects Of Dexmedetomidine On Hemodynamic Parameter

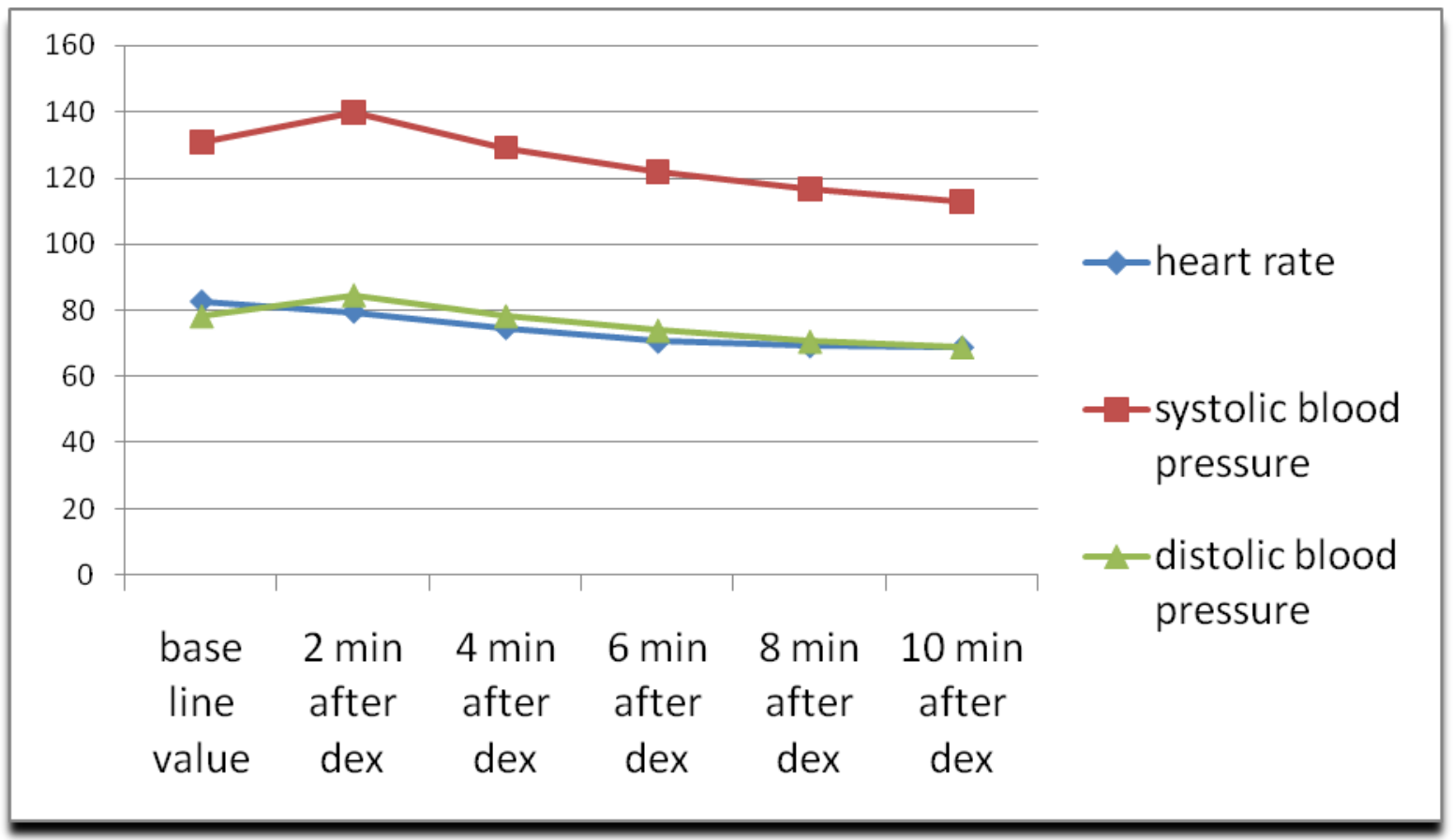

Dex - Dexmedetomidine

\section{DISCUSSION}

Stress response under anesthesia has been universally recognized phenomenon which may be in the form of endocrine or autonomic disturbance. The pressor response to laryngoscopy and endotracheal intubation in form of tachycardia, hypertension and arrhythmias may be potentially dangerous. This hemodynamic change is due to reflex sympathetic discharge caused by epipharyngeal and laryngopharyngeal stimulation. This increase in blood pressure and heart rate are usually transient, variable and unpredictable. Transient hypertension and tachycardia are probably of no consequence in healthy individuals, but either or both may be hazardous to those with hypertension, myocardial insufficiency and cerebrovascular disease. ${ }^{33}$ The periintubation period is one of the most stressing moments of general anesthesia ${ }^{2}$. These changes are the maximum at 1 minute after intubation and last for 5-10 minutes.Stretching of pharyngeal and laryngeal tissue during laryngoscopy as the major causes of haemodynamic response.Stimulation of supraglottic region during laryngoscopy was a major cause of hemodynamic catecholamine response and that contributed to very little additional stimulation.

A wide variety of pharmacological agents were used to attenuate the haemodynamic response:-

$>$ Surface anaesthesia of larynx and pharynx with Lidocaine spray proved unsuccessful because of the need to perform laryngoscopy with resultant stretching and pressure on tissue of larynx and pharynx.

$>$ Lidocaine $1.5 \mathrm{mg} / \mathrm{kg}$ does not markedly attenuate the stress response.

$>$ Deep plane of anaesthesia with volatile agents control changes in heart rate and arterial pressure but it is not useful for rapid sequence intubation may lead to hypotension and prolonged recovery.

$>$ Sodium nitoprusside : $1-2 \mu \mathrm{g} / \mathrm{kg}$

This vasodilator may also lead to intra operative hypotension and

may require invasive arterial pressure monitoring.

$>$ Other drugs like...

- Labetolol : but has long half life

- Diltiazem

- Verapamil

- Nicardipine

- Opoids like Fentanyl, Buprenorphine

The search for ideal technique or agents for attenuation of haemodynamic changes still continues. Complications of pressor responses that follow laryngoscopy include myocardial ischaemia, cardiac failure, intracranial haemorrhage and increase in ICP. 
Studies of hypertensive patients have shown than pressure responses to laryngoscopy is exaggerated in these patients that is associated with a marked increase in nor-adrenaline concentration in the blood ${ }^{37,41}$ Recent studies with alpha-2 adrenoceptor agonists have demonstrated beneficial effects in anesthetized patients. Clonidine attenuates hemodynamic responses during laryngoscopy and endotracheal intubation. It also reduces dose requirements of inhaled anesthetics and potentiates effects of opioids during surgical stimulation. In addition, alpha-2 adrenoceptor agonists may have clinically significant anxiolytic activity. Dexmedetomidine is a highly specific, potent, and selective alpha-2 adrenoceptor agonist.Dexmedetomidine caused a dose-dependent decrease in arterial blood pressure and heart rate (HR), and reduction in sympathetic nervous activity was manifested as a dose-dependent decline in plasma levels of norepinephrine. Single intravenous doses of Dexmedetornidine administered $15 \mathrm{~min}$ before the induction of anesthesia decreased Thiopental requirements, attenuated the hemodynamic responses to laryngoscopy and endotracheal intubation, and diminished Isoflurane requirements. ${ }^{8,10,11}$ The present study was conducted to compare the efficacy of premedication with Dexmedetomidine and Fentanyl on hemodynamic parameters after laryngoscopy and endotracheal intubation. The study was carried out in 100 patients of ASA grade I and II who were divided into 2 groups of 50 each. The first group (group D) was given InjDexmedetomidine $0.6 \mu \mathrm{g} / \mathrm{kg}$ and second group ( group F) was given Inj Fentanyl $2 \mu \mathrm{g} / \mathrm{kg}, 10$ minutes before laryngoscopy and intubation. Hemodynamic parameters like, heart rate, systolic blood pressure, diastolic blood pressure were measured at different time intervals in each patient. The results and observations were recorded and compared

\section{PATIENT DEMOGRAPHICS}

As shown in Table 1, there was no statistical significant difference between the mean age (in years) and mean weight (in kgs) among two groups. The gender distribution was almost equal both groups.

\section{Heart rate}

In both groups the heart rate started decreasing up to 10 minutes after premedication with study drug in respective group. These observations are comparable to those by B. Scheininet $\mathrm{al}^{10}$, A. EsraSagiroglu et $\mathrm{al}^{26}$, Anila D. Malde et $\mathrm{al}^{20}$, Sam Chung et $\mathrm{al}^{9}$, Sukhminderjit Singh Bajwa et $\mathrm{al}^{32}$, Shobhana Gupta et $\mathrm{al}^{31}$, SajithSulaiman et $\mathrm{al}^{33}$. In our study, we observed a decrease of $16.8 \%$ heart rate in Group D and $2.12 \%$ heart rate in group $\mathrm{F}$ from base line value.In both groups, heart rate was increased immediately after laryngoscopy and intubation. However increased in heart rate was more in Group F as compare to Group D.This increase was highly significant $(\mathrm{p}<0.001)$. These observations are comparable to those by Martina Ahoet $\mathrm{al}^{8}$, Sukhminderjit Singh Bajwa et $\mathrm{al}^{32}, \mathrm{~N}$. Turgut et $\mathrm{a}^{22}$. However Sukhminderjit Singh Bajwaet $\mathrm{al}^{32}$ used Dexmedetomidine in dose of $1 \mu \mathrm{g} / \mathrm{kg}$ and $\mathrm{N}$. Turgut et al ${ }^{22}$ used Fentanyl in dose of $1 \mu \mathrm{g} / \mathrm{kg}$.

\section{Systolic Blood Pressure}

After premedication with study drug in respective group systolic blood pressure started decreasing from its baseline value. These observations are comparable to those by Martina Ahoet al ${ }^{8}$, Sukhminderjit Singh Bajwa et $\mathrm{al}^{32}$, PekkaTalke et al ${ }^{14}$, Varshali M Keniya et $\mathrm{al}^{29}$, FerdiMenda et $\mathrm{al}^{25}$, Maria Cristina Smania et $\mathrm{al}^{23}$, John P. Ebert et $\mathrm{al}^{6}$, Sam Chung et al ${ }^{9}$. In our study, we observed a decrease of $13.70 \%$ systolic blood pressure in group D and 6.03\% systolic blood pressure in group F from base line value. In our study, it is evident that the systolic blood pressure was significantly increased in both the groups after laryngoscopy and intubation $(\mathrm{p}<0.05)$. The peak increase in systolic blood pressure was seen just after intubation and cuff inflation (after $1 \& 2$ minute). The increase in systolic blood pressure is less in group $\mathrm{D}$ as compared to group $\mathrm{F}$ and this difference is statistical highly significant $(\mathrm{p}<0.001)$. In contrast to present study result, Martina Aho et al ${ }^{8}$ did not find any difference in blood pressure response between Fentanyl and Dexmedetomidine groups. The systolic blood pressure came back to near normal within 10 minutes post intubation.

\section{Diastolic Blood Pressure}

After premedication with study drug in respective group, diastolic blood pressure started decreasing from its beseline value. These observations are comparable to those by Martina Aho et $\mathrm{al}^{8}$, Sukhminderjit Singh Bajwa et $\mathrm{al}^{32}$, PekkaTalke et al ${ }^{14}$, Varshali M Keniya et $\mathrm{al}^{29}$, FerdiMenda et $\mathrm{al}^{25}$, Maria Cristina Smania et al ${ }^{23}$, John P Ebert et a ${ }^{6}$, Sam Chung et $\mathrm{al}^{9}$. In our study, we observed a decrease of $11.88 \%$ diastolic blood pressure in Group D and 4.68\% diastolic blood pressure in group F from base line value. In our study, the diastolic blood pressure was significantly increased in both the groups after laryngoscopy and intubation $(p<0.05)$. The peak increase in diastolic blood pressure was seen just after intubation and cuff inflation (after $1 \& 2$ minute). The increase in diastolic blood pressure is less in group D as compared to group F and this difference is statistical highly significant $(\mathrm{p}<0.001)$. In contrast to present study result, Martina Aho et $\mathrm{al}^{8}$ did not find any difference in blood pressure response between Fentanyl and Dexmedetomidine groups. The diastolic blood pressure came back to near normal within 10 minutes post intubation. 


\section{Mean Arterial Blood Pressure}

The mean arterial blood pressure was significantly increased in both the groups after laryngoscopy and intubation $(\mathrm{p}<0.05)$. The peak increase in mean arterial blood preesure was seen just after intubation and cuff inflation (after 1\&2 minute). The increase in mean arterial blood pressure is less in group D as compared to group $\mathrm{F}$ and this difference is statistical highly significant $(\mathrm{p}<0.001)$. These observations are comparable to those by Sukhminderjit Singh Bajwaet al ${ }^{32}$ and N.Turgut et al. ${ }^{22}$ However Sukhminderjit Singh Bajwa et $\mathrm{al}^{32}$ used Dexmedetomidine in dose of $1 \mu \mathrm{g} / \mathrm{kg}$ and N.Turgut et al ${ }^{22}$ used Fentanyl in dose of $1 \mu \mathrm{g} / \mathrm{kg}$.

\section{Side effects and complications}

In our study side effects and complications like bradycardia, hypotension, respiratory depression etc encountered were very few and could be easily treated.

\section{CONCLUSION AND SUMMARY}

The present study was carried out "To compare the efficacy of intravenous DEXMEDETOMIDINE and FENTANYL in attenuation of stress response to laryngoscopy and intubation" in 100 adult patients, scheduled for various surgical procedures under general anaesthesia during February 2012 to August 2012 at civil hospital Ahmedabad. After approval from ethical committee of hospital, the patients were randomly divided into 2 groups:

$>$ Group D: Received DEXMEDETOMIDINE $0.6 \mu \mathrm{g} / \mathrm{kg}$ intravenously.

$>$ Group F: Received FENTANYL $2 \mu \mathrm{g} / \mathrm{kg}$ intravenously.

The following observations were made:

[1] It was observed that the heart rate increased after laryngoscopy and intubation in both groups and it started to return to near normal values at the end of 10 minutes post intubation. The increase in heart rate was highly significant in group $\mathrm{F}$ as compared to group D during laryngoscopy and after intubation. Dexmedetomidine produces more significant attenuation of increase in heart rate during laryngoscopy and intubation as compared to Fentanyl.

[2] There is significant increase in systolic blood pressure during laryngoscopy and endotracheal intubation in Fentanyl group as compared Dexmedetomidine group $(\mathrm{p}<0.001)$. Dexmedetomidine produces more significant attenuation of increase in systolic blood pressure during laryngoscopy and intubation as compared to Fentanyl.

[3] There is significant increase in diastolic blood pressure during laryngoscopy and endotracheal intubation in Fentanyl group as compared to the Dexmedetomidinegroup $(\mathrm{p}<0.001)$. Dexmedetomidine produces more significant attenuation of increase in diastolic blood pressure during laryngoscopy and intubation as compared to Fentanyl.

[4] It was seen that with Dexmedetomidine, there is transient increase in blood pressure followed by decrease in blood pressure and heart rate.

Thus it was concluded that DEXMEDETOMIDINE when used as I.V. premedicant in dose of $0.6 \mu \mathrm{g} / \mathrm{kg}$ provides beneficial effect in attenuation of pressor response to laryngoscopy and endotracheal intubation as compare to FENTANYL in dose of $2 \mu \mathrm{g} / \mathrm{kg}$.

\section{REFERENCES}

[1] Dahlgren N, Messeter K.- Treatment of stress response to laryngoscopy And intubation with Fentanyl. Anaesthesia 1981; 36(11): $1022-6$.

[2] Kautto UM. Attenuation of the circulatory response to laryngoscopy And intubation by Fentanyl. ActaAnaesthesiolScand 1982; 26(3): 217- 21 .

[3] D E Martin et al - Low dose Fentanyl blunts circulatory response to tracheal intubation 1982;61:680-4

[4] Dundee JW, Hassard TH. The induction dose of ThiopentoneAnaesthesia 1982; 37: 1176-1184.

[5] Splinter WM - Haemodynamic response to laryngoscopy and tracheal intubation in geriatric patients: effects of Fentanyl, Lidocaine and Thiopentone. C J Anes 1989 jul; 36(4):370-6

[6] J P Ebert -Circulatory response to laryngoscopy: the comparative effects of Placebo, Fentanyl and Esmolol can j anes 1989/36:3/pp 301-6

[7] Aantaa R, Kanto J, Scheinin M, Kallio A, Scheinin H. Dexmedetomidine premedication for minor gynaecologic surgery. AnesthAnalg1990; 73: 230-35

[8] Aho M, Lehtinen A-M, Erkola 0, Kallio A, Korttila K.-The effect of intravenously administered Dexmedetomidine on perioperative hernodynamics and Isoflurane requirements in patients undergoing abdominal hysterectomy. Anesthesiology 1991;74:997-1002

[9] Chung KS, Sinatra RS, Halevy JD, Paige D, Silverman DG.- A comparison of Fentanyl, Esmolol and their combination for blunting the

[10] hemodynamic response during rapid-sequence induction. Can J Anaesth 1992; 39(8): $774-9$.

[11] B. Scheinin, L.Lindgren, T.Randell - Dexmedetomidine attenuates sympathoadrenal responses to tracheal intubation and reduces the need for Thiopentone and preoperative Fentanyl ,BJA 1992; $68: 126-131$ 
[12] Aho M, Scheinin M, Lehtinen AM, et al.- Intramuscularly administered Dexmedetomidine attenuates haemodynamic and stress responses to gynaecologic laparoscopy. AnesthAnalg 1992; 75: 932-9.

[13] Jorgensen BC, Hertel S, Strom J, Hoilund-Carlsen PF, Bjerre-Jepsen K.-Catecholamine response to laryngoscopy and intubation. Anaesthesia 1992; 47(9): $750-6$.

[14] Lawrence CJ, lange SD.-Effects of a single pre-operative Dexmedetomidine dose on Isoflurane requirements and perioperativehaemodynamic stability. Anaesthesia1997; 52: 736-744.

[15] Talke P, Richard Chen, Brian Thomas- The hemodynamic and adrenergic effects of perioperativeDexmedetomidineinfusion in patients undergoing vascular surgery. Anesthesiology2000; 90: 834-839

[16] Yildiz, munise; tavlan, aybars; tuncer, sema; reisli, ruhiye; yosunkaya, alper; otelcioglu, seref.- Effect of Dexmedetomidine on Haemodynamic Responses to Laryngoscopy and Intubation: Perioperative Haemodynamics and Anaesthetic Requirements. Drugs in R \& D 2006; 7: 43-52.

[17] P.E.Tanskanen, J.V. Kytta, T.T.Randell -Dexmedetomidine as an aneasthetic adjuvant in patients undergoing intra cranial tumoursurgary : a double blind, randomized and placebo-controlled study BJA 2006; 97(5):658-665.

[18] Gurbet A, Mogol EB, Turker G.- Intraoperative infusion of Dexmedetomidine reduces perioperative analgesic requirements. CAN J ANESTH 2006; 53: 7: 646-652.

[19] BakhameesHs, HalafawyYm, M El-Kerdawy H, Nevien M Gouda and Altemyatt S - Effect of Dexmedetomidine in morbidly obese patients undergoing laparoscopic gastric bypass. M.E.J. ANESTH 2007; 19 (3): 537-551.

[20] Malde AD, Sarode V.- Attenuation of the hemodynamic response to endotracheal intubation: Fentanyl and Lignocaine. The Internet Journal of Anaesthesiology 2007; 12(1).

[21] Malde AD, Sarode V.- Attenuation of the hemodynamic response to endotracheal intubation: Fentanyl and Lignocaine. The Internet Journal of Anaesthesiology 2007; 12(1).

[22] Hyoung Yong Shin, Jun Woo Kim, A Era Kim - The effects of Lidocaine, Fentanyl, Nicardipine, and Esmolol on hemodynamic and bispectral index response during induction with thiopental sodium Koreananesvol 53, no 3,sept-2007.

[23] N.Turgut, a.turkmen,s.gokkaya - Dexmedetomidine based versus Fentanyl based total intravenous anesthesia for lumbar laminectomy $, 2008,74: 469-74$

[24] Samania MC, Piva JP, Garcia PC. Dexmedetomidine in anesthesia of children submitted to videolaparoscopic appendectomy. Rev Assoc Med Bras 2008; 54(4): 308-13.

[25] Takayuki Kunisawa,Osama Nagata, MichinoNagashima -Dexmedetomidine suppress the decrease in blood pressure during anesthetic induction and blunts the cardiovascular response to tracheal intubation, Clinanesvol 2, issue 3(2009)

[26] Menda F, Koner O, Sayin M, Ture H, Imer P, Aykac B. Dexmedetomidine as an adjunct to anesthetic induction to attenuate hemodynamic response to endotracheal intubation in patients undergoing fast-track CABG. Ann Card Anaesth 2010; 13: 16-21.

[27] A.EsraSaniroglu, MelekCelik, ZeynepOrhon - Different doses of Dexmedetomidine on controlling hemodynamic responses to tracheal intubation, internet journal of anesvol 27: no 2,2010

[28] May S. Al-Sabbagh, Comparative Effects of Fentanyl,Medazolam, Lignocaine and Propranolol on Controlling the Hemodynamic Pressor Response during Laryngoscopy and Intubation, Iraqi J Pharm Sci, Vol.19(2) 2010

[29] Seyed-MohamadMireskandari, NavidAbulahrar, Mohamad-EsmaeilComparison of the Effect of Fentanyl, Sufentanil, Alfentanil and Remifentanil on Cardiovascular Response to Tracheal Intubation in Children, Iranian Journal of Pediatrics, Vol. 20, No. 2, Apri 1-June, 2011, pp. 173-180

[30] Varshali M Keniya, SushmaLadi, and Ramesh Naphade - Dexmedetomidine attenuates sympathoadrenal response to tracheal intubation and reduces perioperative anaesthetic requirement, Indian J Anaesth. 2011 Jul-Aug; 55(4): 352-357.

[31] Sameenakousar, Mahesh, K.V. Srinivasan - Comparisonof Fentanyl and Clonidine for Attenuation of the Haemodynamic Response to Laryngocopy and Endotracheal Intubation, ID: JCDR/2012/4988:2587

[32] Shobhana Gupta, Purvi Tank - A comparative study of efficacy of Esmolol and Fentanyl for pressure attenuation during laryngoscopy and endotracheal intubation, vol 5 issue 1,2011

[33] SukhminderJitBajwa, JasbirKaur, Amarjit Singh - Attenuation of pressor response and dose sparing of opioids and anaesthetics with pre-operative Dexmedetomidine, IJA,vol 56,issue 2,2012

[34] SajithSulaiman, RanjithBasker, Mahesh Vakamudi - The effects of Dexmedetomidine on attenuation of stress response to endotracheal intubation in patients undergoing elective off- pump coronary artery bypass grafting, annals of cardiac anes, vol $15: 1$,jan 2012

[35] Dr.Azam'sAnesthesiology-second edition..chapter 3,page 111

[36] Reid, L. C, and Brace, D.E.1940 Surg. Gynec. Obstet., 70, 157

[37] King BD, Harris LC Jr, Greifenstein FE, Elder JD Jr, Dripps RD. Reflex Circulatory responses to direct laryngoscopy and intubation performed during general anaesthesia. Anesthesiology 1951; 12: 556-66.

[38] Prys-Roberts C, Greene LT, Meloche R, Foex -P. Studies of anaesthesia in relation to hypertension. 11. Haemodynamic consequences of induction and endotracheal intubation. British Journal of Anaesthesia 1971;43:531-47.

[39] Russell WJ, Morris RG, Frewin DB. Changes in plasma catecholamine concentration during endotracheal intubation. Br J Anaesth; 1981, 53:837-9.

[40] D. R. Derbyshire 1983- Plasma catecholamine responses to tracheal intubation. Br. J. Anaesth. 55(9);855-860.

[41] Guignard B- The effect of Remifentanil on the bispectral index change and hemodynamic responses after orotracheal intubation. AnesthAnalg, 2000 jan;90(1):161-7.

[42] Fox E, Sklar GS, Hill G, Villanueva R, King BD. Complications related to the pressor response to endotracheal intubation. Anaesthesiology 1977;47:524-5. 